\title{
ISSUES AND SOLUTIONS STUDY IN THE DAILY MONITORING OF THE SILK ROADS WORLD HERITAGE SITES
}

\author{
Erwu $\mathrm{Li}^{1}$ \\ ${ }^{1}$ ICOMOS International Conservation Centre Xi 'an, Xi 'an 710068, PR.China
}

KEY WORDS: MONITORING, SILK ROADS, WORLD HERITAGE, STAKEHOLDER

\begin{abstract}
:
After the successful inscription into the World Heritage List, the daily monitoring of the Silk Roads heritage sites is facing a dilemma with late start and high predicament. The uneven development of the types of properties, the lack of enthusiasm for grassroots managers and staff, and the blind dependence on hi-technology and notable equipments are the major obstacles to the current day-to-day monitoring efforts. At current stage, increasing capital investment and project funding,actively applying the project and research programs, paying attention to the long-term personnel training, enhancing the management and inspection are the important means to strengthen monitoring. The superior authorities should pay attention to strengthen the support of the projects and establish the accountability machanism. While the heritage management administrations need to continue to fully emancipate the mind on the basis of recognising the importance, optimise the existing mechanism, and undertake the daily monitoring work on its own or entrusting a professional company, organisation or institution. Moreover, they should strive to achieve a comprehensive and healthy development while complementing the shortcomings.
\end{abstract}

\section{INTRODUCTION}

Heritage monitoring consists of daily, periodic and reactivity monitoring. Among them, daily monitoring implemented by the grass-roots management units, is the top priority for the longterm protection and conservation for heritage sites. The daily monitoring includes the main body conservation status of cultural heritages, changes in natural and human factors within the heritage and buffer zones, the development impact of the surrounding areas, and the capacity of tourists etc(Zhou, 2015). Drawing on "the Silk Roads: The Routes Network of Chang'an - Tianshan Corridor" component properties in China (hereinafter as Silk Roads heritage), which was succesfully inscribed on the World Heritage List in 2014 jointly nominated by China, Kazakhstan and Kyrgyzstan, this article explores solutions to the issues encountered in the process of implementing daily monitoring work of the Silk Roads heritage management units(administrations).

\section{THE STATUS QUO OF DAILY MONITORING OF} THE SILK ROADS HERITAGE

\subsection{Inspections and Tourist Management as Mainstay}

Monitoring as a crucial indicator and approach for the inspection, evaluation and lasting conservation of the World Heritage, has gradually grabbed attention of Silk Roads heritage management units in recent years. Dring the last decades, heritage sites mainly conduct routine patrols and tourist management with some monotonous and infrequently-applied technical and research monitoring involved. For recent years, along with the nomination process of the Silk Roads heritage, under the guidance of the National Cultural Heritage Administration of China (Hereinafter as NCHA) and the financial support from the management authorities in all levels, daily monitoring in accordance with the Operational Guidelines for the Implementation of the World Heritage Convention and China World Cultural Heritage Monitoring Management
Measures have been imposed on the conservation and management work for the properties.

The daily monitoring overall improves the management and conservation by practicing three-layer monitoring on the national, provincial and the property units, and two-layer inspection mechanism on the national and provincial level. At the current stage, the daily monitoring of the Silk Roads heritage mainly focuses on routine patrol and tourist management, assisted by some monitoring methods designated for the heritage body, natural environment and human factors.

1.2 Specific focuses of respective properties

Each property has its particular value, conservation techniques, and relations with natural and human factors(NCHA and IICC$X, 2015)$ It requests specific focuses in daily monitoring(Zhang, 2011). For example, as for the grotto temples represented by Maiji Mountain, Bingling Temple and Bin County Cave Temple, natural disasters are the biggest enemies with tourist factors ranked the second. Therefore, the monitoring primarily emphasises on meteorological and hydrological factors and wind erosion, followed by the monitoring of carbon dioxide microenvironment inside the grottoes released by the tourists. Taking large earthen sites as an example, due to their massive scale, it is difficult to monitor the rammed earth remains overground and underground, as well as the human factors within the large territory. Consequently, the daily monitoring focuses on patrols and tourist management. On the contrary, architectural properties such as the Small and Great Wild Goose Pagodas are relatively stable. In addition to daily patrol and tourist management, the monitoring focuses on regular monitoring of the heritage body (such as sedimentation, water damage, alkalisation, disease, etc.).

\subsection{Basic Requirements at Current Stage}

The Silk Roads heritage feature a wide span, large volume, and diverse variety. Unlike the Grand Canal, Suzhou Garden and 
other World Heritage sites in China with relatively fixed monitoring objects, the Silk Roads heritage have no concrete and systematic monitoring indicators and factors given their diversity and many other factors. At the current stage, each property should properly keep records on the aspects including daily meteorological and hydrological indicators, temperature and humidity (micro-environment for grottoes), tourist capacity and behavior, and management dynamic. Besides, each property should practically conduct daily inspections within the heritage body, heritage areas and buffer zones (especially for large sites) while taking photos for the body and its fragile and changing part. The requirement of basic daily monitoring could then be satisfied in this manner.

\section{ISSUES}

In recent years, China has made great progress in the Silk Roads heritage monitoring with fruitful achivements. However, the rapid development uncovers some problems. In light of daily monitoring of the Silk Roads heritage, the major issues are: (1) Insufficient attention; (2) Lack of initiative on the grassroots staff; (3) Unbalanced monitoring objects; (4) Technical facilities being over-valued in some properties.

\subsection{Insufficient Attention Given to Daily Monitoring}

After the successful inscription, some grassroots management administrations have attached less importance to daily monitoring. In fact, the grassroots leadership should have acknowledged the importance of the work, since been experienced the world heritage nomination process and received repeated instructions from the superior. However, considering the long lasting and tedious while yielding meagre outcomes for quite some time, some decision makers are preferably to focus on time-efficient management and operation, instead of daily and routine monitoring.

\subsection{Lack of Enthusiasm Among Grassroots Staff}

Human resources are generally inadequate in the Silk Roads heritage management administrations at the basic level. Grassroots staff often wear multiple hats with limited salaries. Although many heritage sites can ensure patrol and tourist management at some extent, the daily monitoring records for the heritage body and for meteorological and hydrological indicators were not implemented due to the lack of enthusiasm and subjective initiative among their staff.

\subsection{Unbalanced Monitoring Content}

World Heritage monitoring should be developed collectively in three aspects: system, technology and scientific research(Li, 2013). Although the monitoring contents vary among respective properties, the current monitoring presents an unbalanced trend. For example, the grottoes have invested greatly in the technical monitoring and the management of macro and micro environment, mainly referring to the theoretical system and experience of Mogao Caves, but have yielded with limited results for their own. The routine patrol and tourist management of great sites occupy most human resources, hence their technical and research is inevitably hard to improve. As for architectural heritage sites, in order to ensure their lasting safety, great attention needs to be paid to the monitoring in the aspects of natural disasters, underground water level, sedimentation and cracks etc., while the technical monitoring of the microenvironment is often ignored.

\subsection{Hi-technology Over-valued in Some Properties}

Some heritage sites management administrations unilaterally emphasis on technical means in daily monitoring, regarding high-tech equipment as the exclusive standard for assessing the quality of the work and the necessity for obtaining data, thus various hardware and software have been handsomely purchased. It could be explained by tracing back to the introduction of monitoring as a new concept to the management and conservation, people tended to adopt advanced technologies for the work, without fully understanding the needs and resources of properties and the capacity of staff. Ever after the high-tech equipment have been installed and operated for some time, the according management lags behind (Zhao, 2007). The staff responsible for the maintenance and data recording becomes reckless due to the lack of enthusiasm. Eventually, the costly equipment become "face-saving effort and useless decoration".

\section{SOLUTIONS}

\subsection{Strengthened Attention and Financial Support from the Superior Management Administrations}

The grass-root management administrations should actively apply for monitoring projects. The superiors, national, provincial and municipal cultural heritage authorities should further focus on the daily monitoring of the Silk Roads heritage, increase funding, and compile annual work plans with emphasis on monitoring and management. In the meantime, in face of the loopholes of the practical work and management, the administrations should also be guided and encouraged to apply for technical research and monitoring projects in a targeted manner. For example, the project"Improving the daily monitoring and management of the Grottoes Temples of the Silk Roads: the Routes Networks of Chang'an-Tianshan Corridor"could be included in NCHA's annual working plan; After the coordination and discussion with multiple parties, the Conservation and Management Office of the Bin County Cave Temple could consider to apply for funding with the subject of "Monitoring the Groundwater Micro-environment and Derived Biological Diseases". By doing so, they can carry out routine monitoring of groundwater level, water quality, temperature and humidity, animals, plants, and microorganisms. This not only improves and strengthens the technical monitoring capability and the level of the management, but also lay a data foundation for the next step in applying for the further monitoring of cultural heritage conservation research projects in the future. In 2016, the Site of Dingding Gate, Luoyang City of Sui and Tang Dynasities had completed its compilation of the "Project Proposal of the Monitoring and Early Warning System for the Site of Dingding Gate", successfully gained the special subsidy of national cultural heritage conservation, laying a good start for the application of such projects.

Meanwhile, the research department or personnel of each cultural heritage administration should include the daily monitoring staff into the study, arrange them to participate in the research and applications. In the final outcomes (published papers or other forms of research achivements), their names should be listed ahead. This would be an important basis for the future evaluation of professional titles and scientific research awards. This is to take the application and implementation of monitoring projects as an opportunity to encourage grass-roots staff by sharing scientific research achievements, so as to stimulate them to play a more proactive role in the daily monitoring work. 


\subsection{Regular and Normalised Training}

The training objects include the managers and staff of the properties who are undertaking the specific work. Objectively, it takes time to let the decision-making and the grass-roots units of the management administrations realise the importance of daily monitoring and consciously take proactive actions to implement effectively. Training on this matter should not be limited to limited meetings and lectures organised by the cultural heritage authorities, but to form a regular and normal mode. It is suggested that the Secretariat responsible for the overall conservation and management of the Silk Roads Heritage should take the initiative, and the provincial (autonomous region) cultural heritage authorities should actively cooperate with each other to ensure that at least one monitoring training course to be held quarterly for the management and grass-roots units, including personnel, professional and technical training. After training, it is necessary to organise the personnel responsible for daily monitoring for in-depth exchange and experience sharing(Wang, Kong, 2016).

\subsection{Establish a Vertical Accountability Mechanism}

Establish a vertical accountability mechanism for the daily monitoring of the Silk Roads heritage, from National, Provincial (autonomous region), Municipal, to County(Sites)level cultural heritage administrations, to be compiled and implemented by $\mathrm{NCHA}$ (Wang, 2016). At present in China, at the law and regulation level,"China World Heritage Monitoring and Inspection Management Measures" and the "China World Heritage Monitoring Regulations (Draft for Solicitation of Comments)"had been issued. However, procedures and details of the Silk Roads heritage monitoring is still under discussion. In terms of daily monitoring, in order to ensure the authenticity and comprehensiveness of data, a top-down accountability mechanism is indispensable. Cultural heritage authorities and administrations at all levels should appoint the responsible person. Any violation of the regulations, failed to report on time, concealment or tampering of monitoring results, etc. should be investigated and immediately implement the accountability procedures once identified. If violations of regulations are verified, the responsible institutions and persons shall be publicised and included in the annual assessment results; in case of any serious consequences, the units and personnel should be reported to NCHA and pursue further accountability.

\subsection{Maintain and Strengthen Daily Patrol Management} and Establish Daily Monitoring Procedures

The main purpose of the patrol is to passively monitor and inspect cultural heritage through external supervision, so as to prevent and avoid the harm to the heritage. On the basis of continuing to maintain daily inspection and management, each property should further increase the monitoring and recording of the heritage site. In the meantime, with the value and attributes of the heritage as the core, they should fully communicate with the experts and technicians, and compile the "XXX Daily Monitoring Procedures (Trial)", to incorporate daily monitoring factors and indicators into the patrol. They should continuously improve and enrich the work content practically, gradually integrate the active monitoring with external supervision and inspections, transforming passivity into initiative, so as to fundamentally prevent the harm to the heritage. In addition, the grassroots supervision system is very crucial. Each heritage management administration should set up a dedicated post to be responsible for daily supervision(Ma, 2008). At the same time, members of the leadership team should inspect the implementation of specific work from time to time, review monitoring reports and photo records, etc., to make these data an important basis for annual and periodic rewards and punishments.

\subsection{Economic and Useful Monitoring Facility}

For the daily monitoring at current stage, high tech equipment is the icing on the cake rather than timely help. To meet with the actual needs, affordable and simple tools are often more direct and effective than expensive digital hardware and software. On the basis of mobilising the daily monitoring personnel, each heritage management administration should, according to their own needs, purchase motorcycles or electric vehicles and digital cameras to facilitate their daily patrol and inspection, as well as the basic heritage monitoring facilities, such as small meteorological stations with simple wind direction reader, temperature and humidity meters to record the daily weather. The above requirements may look simple, but in fact, the grassroot decision-makers should take a simple and solid step in line with the attitude of being practical and realistic, refusing vanity projects, with normalised daily monitoring as the goal.

The administrators of the properties should fully realise that people are the basis of daily monitoring and the guarantee of heritage conservation. For those already equipped with hi-tech facilities, no matter how costy and multi-functional, are a pile of scrap without people's use and maintenance. According to the current demand, the grassroot managers could selectively choose the basic indicators and main functions needed in the existing monitoring facilities, in order to reduce the workload and alleviate the personnel; Some equipments that are complicated and fragile, expensive to maintain, can be sealed for future use.

\subsection{Entrust the Professionals}

It is also within the scope of this paper for the property managers to entrust the professional company, organisation or institution to take charge of the daily monitoring work. The main advantages are as follows: 1)Companies, organisations and institutions with cultural heritage monitoring as their main business have indisputable advantages over the nonprofessional staff of heritage management staff, from the perspectives of theory, skills and practical experience; 2)According to the actual situation of each heritage site, daily monitoring workload can be accomplished by several professionals instead of a non-professional team, such, which can save human resources and training costs in the long run; 3)By doing so, the heritage management administrations would no longer hold the accountability for monitoring.

To entrust the professional requires the property managers to fully emancipate their minds, get rid of the "housekeeper" theory, stand in the perspective of "professional work should be entrusted to the professionals", and consider the long-term, benign and professional conservation and management mode of heritage sites from a higher level. With a responsible attitude towards the world heritage conservation and the whole society, professional work can totally be entrusted to the pros.

To implement the daily monitoring with a pro, the following should be reminded: 1) Comprehensively consider various factors, to specify the responsibilities and obligations of the employee and employer in the contract, and to avoid possible disputes on accountability and financial issues; 2) Organise seminars among the management administration, experts and the entrustee to fully consider the monitoring standards and contents, determine the monitoring indicators and factors, 
formulate detailed reports, and constantly improve the report contents during practice; 3)Set up a special person to supervise and organise the mid-term and final assessment while the assessment results should be directly linked to the settle accounts; 4) Be alerted to the purchase of high-tech equipment, software and hardware. In many cases, simple and economical facilities are sufficient for daily monitoring with long-term sustainability.

3.7 The "State of Conservation" and "Periodic Report" for World Heritage Sites Of UNESCO

The UNESCO World Heritage Center requires the states parties to provide the "State of Conservation" (Hereinafter as SOC) of all world heritages sites within its territory every each year, and the "Periodic Report" (Hereinafter as PR) every six years. Monitoring occupy a considerable length of both reports. The SOC is a direct summary of the daily monitoring and management data of the property, while the PR focuses on the trends and problems revealed by various types of data. At present, entrusted by NCHA, the ICOMOS Xi'an International Conservation Center (the Secretariat of the Coordinating Committee on the Serial World Heritage Nomination of the Silk Roads) has successfully compiled three SOCs and one PR for the World Heritage of "The Silk Roads:Routes Network of Chang'an-Tianshan Corridor".

The basic data of the reports depend on the daily monitoring outcomes. Therefore, under the supervision of the national, provincial and municipal cultural heritage authorities, the heritage managers have to pay attention to such work and provide monitoring data on time and in quantity to facilitate the completion of the tasks assigned by the superiors. Although some data may not be entirely authentic and complete, at the macro level, the two reports do play a role in promoting the daily monitoring of the Silk Roads heritage. It is recommended that NCHA organises experts to evaluate the reports and irregularly dispatches inspection teams to verify the authenticity, validity and completeness of the data, with awarding the heritage management administrations and personnel that being evaluated as effectively monitoring. On the other hand, the units seriously failed to undertake the monitoring work, and those who are found with fraudulent practices must be notified and criticised.

\section{CONCLUSION}

Each level of the Silk Roads heritage management authorities and administrations should keep alerted of the existing issues and deficiencies in their daily monitoring, look up to their domestic and international peers(Sun, 2008).. At the recognition level, all technological methods are tools and paths to help people achieving their goals. The foundation of heritage monitoring is people, the subjective consciousness and capability of the people is decisive. At the technical level, managers of all properties should recognise the current stage and choose economical, simple and effective equipment according to their current demands. It requires the administrations to schedule and implement daily monitoring with people as the basis, with the perspectives of the personnel in charge of the duty, considering their awareness, capability, knowledge structure, and especially their practical needs. On the basis of complying with the current social environment and laws and regulations in China, the administrations should focus on exploring and trying a variety of incentives to mobilise their staff.

\section{REFERENCES}

Guozhe Zhou, 2015. Some Thoughts about Cultural Heritage Monitoring and Management. China National Exhibition, 2015(12), 235-237.

NCHA (National Cultural Heritage Administration of China), IICC-X (ICOMOS International Conservation Centre-Xi'an), 2015. Report on the state of conservation: The Silk Roads: Routes Network of Chang'an-Tianshan Corridor(China). UNESCO World Heritage Centre, 2015(1), 002

Rouran Zhang, 2011. Discussion on Valuation and Monitoring Systems for World Heritages, Landscape and Environment Planning, 35(1), 36-42.

Songsong Li, 2013. Three Reflections about World Heritage Monitoring. China Cultural Relic News, 02(22), 006

Peng Zhao, 2007. Some Thoughts about World Cultural Heritage Monitoring and Management. The Paper Collection of the 7th Academic Annual Meeting of China Association for Conservation Technology of Cultural Heritage, 2007(1), 344.

Qian Wang, Feifei Kong, 2016. Issues and Countermeasures of the World Heritage Monitoring Work, Cultural Journal,70(8):133-134

Zhaoguo Wang, Zhaoping Yang, Xiaoliang Xu, 2016. Analysis of Threats to World Heritage , Arid Land Geography (Chinese Version), 39(1), 224-232.

Chaolong Ma, 2018. The Discussion of Establishing World Cultural Heritage Monitoring System in China. Paper Collection of the Academic Seminar of the Chinese World Heritage Career under the Globalisation and World Heritage Forum.2018(1), 63-64.

Keqin Sun, 2008, Study on Protection and Sustainable Development of the World Heritage in China. Journal of China University of Geoscience(Social Science Edition), 8(5), 36-40. 